\title{
8
}
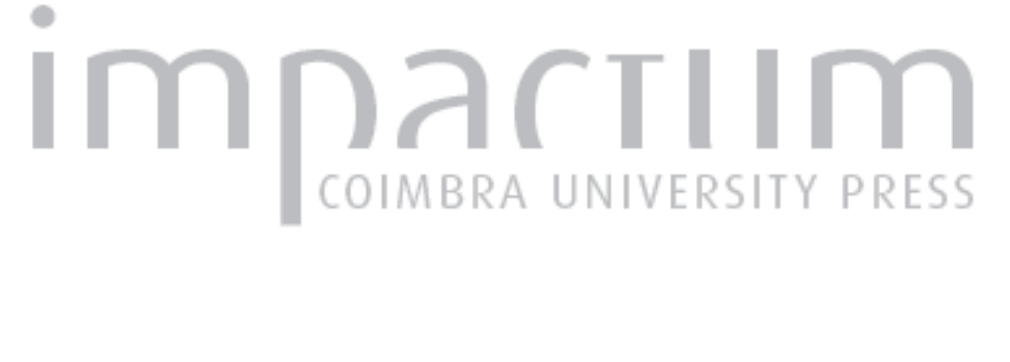

\section{O meio ambiente sadio e ecologicamente equilibrado como direito humano e a ética ambiental}

\author{
Autor(es): $\quad$ Pestana, Liliane Moraes
}

Publicado por: Universidade Católica de Petrópolis

URL persistente:

URI:http://hdl.handle.net/10316.2/33901

DOI:

DOI:http://dx.doi.org/10.14195/2175-0947_1-1_3

Accessed : $\quad$ 26-Apr-2023 13:37:24

A navegação consulta e descarregamento dos títulos inseridos nas Bibliotecas Digitais UC Digitalis, UC Pombalina e UC Impactum, pressupõem a aceitação plena e sem reservas dos Termos e Condições de Uso destas Bibliotecas Digitais, disponíveis em https://digitalis.uc.pt/pt-pt/termos.

Conforme exposto nos referidos Termos e Condições de Uso, o descarregamento de títulos de acesso restrito requer uma licença válida de autorização devendo o utilizador aceder ao(s) documento(s) a partir de um endereço de IP da instituição detentora da supramencionada licença.

Ao utilizador é apenas permitido o descarregamento para uso pessoal, pelo que o emprego do(s) título(s) descarregado(s) para outro fim, designadamente comercial, carece de autorização do respetivo autor ou editor da obra.

Na medida em que todas as obras da UC Digitalis se encontram protegidas pelo Código do Direito de Autor e Direitos Conexos e demais legislação aplicável, toda a cópia, parcial ou total, deste documento, nos casos em que é legalmente admitida, deverá conter ou fazer-se acompanhar por este aviso.

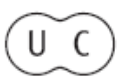



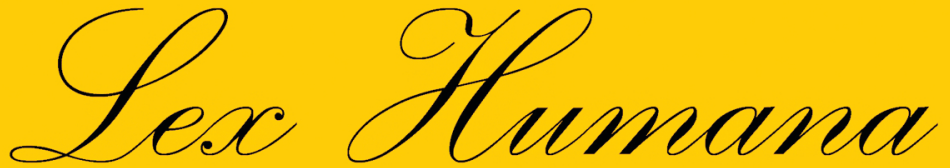

Revista do Programa de Pós-Graduação em Direito da UCP

ISSN(e) 2175-0947

Universidade Católica de Petrópolis Rua Benjamin Constant, 213 - Petrópolis - Centro CEP 25610-130

Tel: (24) 2244-4000 E-mail: lexhumana@ucp.br 


\section{O MEIO AMBIENTE SADIO E ECOLOGICAMENTE EQUILIBRADO COMO DIREITO HUMANO E A ÉTICA AMBIENTAL}

\section{Liliane Moraes Pestana}

\section{Introdução}

No estado natural, onde não havia leis, onde não havia Estado enquanto governo, o objetivo maior do ser humano era a sobrevivência, a manutenção da sua vida, da sua própria existência. Logo, era a força que permitia defender a sua vida, que permitia impor a sua vontade sobre a do outro. Assim, surgia o direito natural.

O direito natural, por sua vez, seria composto de um conteúdo mínimo, conteúdo este que seria responsável pelo elo existente entre Moral e Direito. Contudo, para poder falar-se em um conteúdo mínimo do direito natural, há que se partir necessariamente do pressuposto de que o objetivo normal ou natural da sociedade é a sobrevivência.

Neste estado natural, algumas medidas sociais deveriam ser observadas a fim de que fosse possível alcançar essa meta, ou seja, a sobrevivência e, dentre elas, algumas poderiam ser qualificadas como leis naturais, que seriam aquelas regras de conduta que toda organização social deveria respeitar para ser viável a sua existência. Estas normas passam, então, a constituir um elemento comum entre o Direito e a Moral convencional de todas as sociedades, sendo a base pra a realização do propósito de sobrevivência que é buscado pelos homens quando se associam, tanto para as normas jurídicas como para a moral ${ }^{1}$.

Contudo, esse estado de natureza, não obstante o exercício mais pleno pelo homem da sua liberdade, era um estado frágil e, até mesmo, perigoso. Em conseqüência, os indivíduos passaram a se unir e abriram mão de parte das suas liberdades para, através de um contrato social, conferir a um ente 1 Análise feita por Eusebio Fernandez da postura de Hart sobre a conexão necessária entre a Moral e o Direito e a sua teoria do conteúdo mínimo do Direito Natural. FERNANDEZ, Eusebio. Teoria de la justicia y derechos humanos. Madrid: Editorial Debate, 1991. pp. 70-71. 
moral a regulação das suas vidas, alicerce este das teorias contratualistas de Thomas Hobbes, Rousseau e Locke. Teoria do contrato social que explica a origem da sociedade e do poder político através da passagem do estado de natureza para a sociedade civil e política.

O Estado passa a ser a organização desse poder social e a ele cabe garantir a segurança dos indivíduos.

Todavia, face às atrocidades praticadas por este mesmo Estado, aos privilégios concedidos a poucos e ao totalitarismo e autoritarismo dos regimes absolutistas, predominantemente ao longo da Idade Média e Moderna, várias manifestações desenvolvem-se a fim de reivindicar o respeito e a salvaguarda dos direitos humanos que passam a estar contextualizados, positivados em diversas Declarações e Constituições.

Estes direitos humanos são exatamente esses direitos naturais, os direitos inatos, direitos individuais, direitos do homem e do cidadão, também chamados de direitos fundamentais, direitos públicos subjetivos, liberdades fundamentais ou liberdades públicas. Ao dizer que são direitos fundamentais, pretende-se destacar que se encontram eles estreitamente conectados com a idéia de dignidade humana e são ao mesmo tempo as condições de desenvolvimento dessa idéia de dignidade ${ }^{2}$.

Os direitos humanos lidam, pois, com os aspectos mais valorados da sociedade humana, visto que, sem a sua tutela, a própria vida e dignidade humana quedam-se inviabilizadas, com características próprias que devem ser respeitadas: imprescritíveis, inalienáveis, irrenunciáveis, invioláveis, universais, interdependentes e complementares ${ }^{3}$.

Desde o século passado, no entanto, os direitos humanos encontramse em situação paradoxal eis que, não obstante o seu reconhecimento em diversos textos legais, que proclamam um número crescente de direitos civis, políticos, sociais, econômicos e culturais, que constituem, na história

2 Ressalta o autor acima já mencionado que por trás de cada terminologia encontra-se uma concepção jurídico-política distinta. Contudo, assevera a sua preferência pela denominação de direitos fundamentais do homem por expressar que toda pessoa possui os direitos morais pelo fato de ser um indivíduo e que estes devem ser reconhecidos e garantidos pela sociedade, pelo Direito e pelo poder político, sem nenhum tipo de discriminação social, econômica, jurídica, política, ideológica, cultural ou de sexo. FERNANDEZ. Op. cit., p. 78.

3 PAIM, Maria Augusta Fonseca. Direitos Humanos e Meio Ambiente.

Revista Jurídica. Campinas: Faculdade de Direito da PUC de Campinas, v. 19, n. 1, 2003. p. 60. 
do direito, a afirmação mais acabada da crença do homem na sua própria dignidade; esses mesmos direitos, infelizmente, transformam-se em ideais utópicos, na medida em que são sistematicamente desrespeitados por grupos sociais e governos ${ }^{4}$.

Esta situação é mais evidente quando se cuida da questão ambiental. Atualmente, como legado do colonialismo predatório, da revolução industrial desorganizada, do valor puramente utilitário e mecanicista que foi conferido à natureza ao longo da história das civilizações, considerada como objeto, como mercadoria a ser consumida, evidencia-se, cada vez mais, o agravamento nas condições do equilíbrio ambiental. Danos irreversíveis foram cometidos, verdadeiros ataques desmedidos ao meio ambiente que, por sua vez, reage através de fenômenos que não se consegue ainda compreender, como é o caso recente da tsunami, em dezembro de 2004, ou dos furacões que ganham intensidade e devastam cidades, como o ocorrido em Nova Orleans, em 2005, o que demonstra a falta de harmonia e o desequilíbrio latente da natureza.

Despertou-se, portanto, a consciência de que uma vida digna requer um cuidado com sua qualidade e com aspectos da coletividade de modo que o conceito de direitos humanos foi ampliado, dando origem aos direitos de solidariedade ou fraternidade, onde podemos incluir o direito ao meio ambiente sadio e equilibrado.

$\mathrm{O}$ presente trabalho pretende apresentar, primeiramente, os direitos humanos em sua origem e evolução histórica, comentando a sua fundamentação, para, posteriormente, traçar um paralelo com o meio ambiente enquanto direito humano de $3^{\mathrm{a}}$ geração, analisando o direito ao meio ambiente equilibrado como direito fundamental, tal qual é previsto pelo ordenamento jurídico brasileiro, para, por fim, lançar alguns conceitos e teorias concernentes à ética ambiental, reforçando a necessidade de mudança de paradigma do homem frente à natureza, de modo a preservá-la para as presentes e futuras gerações.

\section{Os Direitos Humanos}

\subsection{A evolução histórica}

Somente a partir do momento em que limites foram impostos ao poder do Estado é que o conceito de direitos humanos firmou-se na 4 BARRETO, Vicente. Os Fundamentos Éticos dos Direitos Humanos. Revista de Direito Comparado, Belo Horizonte, v. 2, n. 2, março, 1998, p. 343. 
história, o que foi a base das revoluções liberais dos séculos XVII e XVIII, ao estabelecer o postulado da liberdade do indivíduo e o reconhecimento e proteção da dignidade da pessoa humana como direitos fundamentais do homem ${ }^{5}$.

Contudo, considerar, como pretendem alguns autores, que a origem dos direitos humanos deu-se com o balizamento do Estado pela lei é equivocado. Apesar de não ter conhecido o primado da liberdade individual, na Antiguidade Clássica, Grécia e Roma antigas desenvolveram, já naquela época, algumas idéias sobre o conceito de democracia e república, derivando concepções de participação popular na formação da vontade do Estado e de limitação de poder ${ }^{6}$.

A divulgação do cristianismo também contribuiu muito para a formação das bases originárias dos direitos humanos, divulgando a idéia de existência de uma igualdade natural entre os homens, uma vez que, sendo o homem criado à imagem e semelhança de Deus, seria ele portador de uma natural dignidade. Possui, portanto, o homem, alto valor intrínseco e uma liberdade inerente à sua natureza, detentor de direitos que devem ser respeitados por todos e pela sociedade política, como bem defendeu São Tomás de Aquino, em seus ensinamentos, baseando-se em um direito natural ${ }^{7}$.

Ao longo da Idade Média, a divisão em estamentos da sociedade gerou muitas injustiças, não havendo igualdade jurídica e predominando os privilégios concedidos aos poucos.

Diante desse quadro que foi editada a Magna Carta, na Inglaterra, em 1215, pelo Rei João Sem Terra, com finalidade de limitação do seu poder, muito embora tenha sido um documento de proteção dos direitos das classes privilegiadas. Sua importância reside no fato de ter sido após a sua edição que as liberdades dos ingleses foram se afirmando no decorrer da história, e nela foram previstos princípios relevantes como o

$5 \quad$ CARVALHO, Oscar de. Gênese e Evolução dos Direitos Humanos Fundamentais. Revista do Instituto de Pesquisas e Estudos - Divisão Jurídica, Bauru, n. 34, abril/julho, 2002. p. 31.

6 Ibidem. p. 33.

7 Ibidem. p. 34-35. 
due process of law, na cláusula $39^{8}$, dentre outros ${ }^{9}$.

Verifica-se, desse modo, que o tema dos direitos humanos, em seu nascedouro, esteve diretamente associado à necessidade de se reduzir a excessiva interferência do Estado na vida dos cidadãos ${ }^{10}$.

Contudo, somente com as revoluções inglesas, americana e francesa é que se vislumbra o primeiro momento de afirmação propriamente dita dos direitos humanos em nossa história, pelo que, passamos a discorrer um pouco acerca de cada uma delas e seus principais legados.

A história inglesa, ao longo século XVII, está permeada de luta entre o rei e o Parlamento.

Em 1628, foi submetida ao rei Carlos I a Petição de Direitos - Petition of Rights - pela qual algumas questões não poderiam ser executadas sem autorização parlamentar, muito embora não tenha sido cumprida. Em 1679, o Parlamento votou a Lei do Habeas Corpus, visando à garantia das liberdades individuais. Em 1688 ocorreu a Revolução Gloriosa e Guilherme de Orange foi coroado rei, tendo sido obrigado a assinar a Declaração de Direitos - Bill of Rights - que colocou fim ao absolutismo e instaurou a monarquia parlamentarista ${ }^{11}$.

O advento do Iluminismo, nos séculos XVII e XVIII, tendo em John Locke seu principal inspirador, "desenvolveu-se um jusnaturalismo de cunho racional, o qual preconizava, em síntese, ser o homem titular de direitos naturais inatos, que seriam eternos e inalienáveis, restringindose o papel do Estado a garantir o exercício dessas liberdades (direitos negativos)". ${ }^{12}$

Com base nesta nova ideologia e em conseqüência das opressões que a coroa inglesa impunha às treze colônias, em especial a cobrança de tributos exorbitantes e o impedimento do livre comércio, desenvolveu-se

8 "Nenhum homem livre será detido ou preso, nem privado de seus bens, banido ou exilado ou, de algum modo, prejudicado, nem agiremos ou mandaremos agir contra ele, senão mediante um juízo legal de seus pares ou segundo a lei da terra".

9

CARVALHO. Op. cit. p. 36.

10 GABRIEL, Antônio José Martins. Direitos humanos e globalização: conquistas e desafios. Revista do Ministério Público, Rio de Janeiro, n. 19, jan.I jun., 2004. p. 40.

11 CARVALHO. Op. cit. p. 37-38.

12 GABRIEL. Op. cit. p. 40. 
a Revolução Americana. Em 4 de julho de 1776, houve a Declaração da Independência onde estão firmados os postulados do governo consentido, baseado na vontade popular e da existência de direitos inatos e inerentes a todos os homens. Sua base filosófica consiste na noção de que o indivíduo possui direitos anteriores e superiores ao Estado, conforme as formulações jusnaturalistas. Em 1783, Inglaterra assinou o Tratado de Versalhes, reconhecendo a independência das treze colônias ${ }^{13}$.

A Constituição americana, após inúmeros debates, acabou sendo ratificada por todos os Estados, em 1787, e implantou pela primeira vez na história o presidencialismo e a federação e estabeleceu a tripartição dos poderes. Em 1791, foram editadas as dez primeiras emendas à Constituição, conhecidas como Bill of Rights daquele país. Foram previstos, só para citar alguns direitos, a liberdade de imprensa, de religião e de reunião, os direitos dos acusados e a inviolabilidade das pessoas contra busca e apreensão arbitrárias, proibindo-se penas cruéis e as finanças exageradas, além de outros direitos fundamentais ${ }^{14}$.

A Revolução Francesa, por sua vez, teve o mérito de pôr fim a toda uma ordem social vigente, ao regime absolutista e aos privilégios remanescentes do Antigo Regime.

A sociedade, dividida em castas - nobreza, clero e o restante da população - obrigava que toda a carga tributária recaísse sob o Terceiro Estado, afora a isenção de impostos e o gozo de favores, tais como cargos públicos e pensões, que eram concedidos ao Primeiro e Segundo Estados. Tudo isso foi fator para gerar revolta e indignação na população, principalmente, na burguesia que começava a se firmar como uma classe detentora de poder econômico que se via em situação desprivilegiada por não ter influência política, passando a reivindicar a mesma.

A revolução veio para pôr fim a esse quadro e estabelecer a igualdade de todos perante a lei. Igualdade esta que foi meramente jurídica e de natureza formal.

A Declaração dos Direitos do Homem e do Cidadão, de 1789, traduz o espírito da revolução francesa e teve como base a teoria contratualista e os ideais do jusnaturalismo, garantindo os direitos do cidadão burguês - igualdade perante a lei e o direito de propriedade - e a liberdade individual e direitos do indivíduo em face do Estado. Porém, 
os problemas das classes menos favorecidas não foram resolvidos ${ }^{15}$.

Todo esse novo cenário proporcionou o desenvolvimento do capitalismo moderno que tinha duas novas classes sociais em constante disputa: a burguesia, detentora dos meios de produção, e o proletariado, que possuía apenas a sua força de trabalho como mercadoria.

Pregava-se a não intervenção estatal na economia, nos moldes do liberalismo clássico, sendo o próprio mercado o responsável pelos rumos das relações econômicas e sociais, bem como, afigurando-se como atentado à liberdade individual e à lei do contrato toda e qualquer intromissão ocorrida.

As desigualdades e segregação sociais foram agravando-se, principalmente durante a Revolução Industrial, nos séculos XVIII e XIX. As condições de trabalho eram deploráveis, insalubres e cruéis, explorando-se crianças e mulheres em jornadas de trabalho excessivas, $\mathrm{o}$ que se refletiu diretamente nas péssimas condições de vida.

Friedrich Engels retratou bem essa situação em sua obra "A Situação da Classe Trabalhadora na Inglaterra", tendo convivido de perto com os bairros miseráveis e afetados pela falta de infra-estrutura, de circulação de ar, repletos de epidemias, higiene comprometida e residência da grande maioria dos trabalhadores das indústrias que não tinha meios para se sustentar.

Para fins de ilustrar o que foi um pouco da situação vivenciada pelos ingleses em meados do século XIX, passo a transcrever um trecho da obra citada, quando do exame do chamado "Ninho de Corvos", o bairro St. Giles:

St. Giles fica no meio da parte mais populosa da cidade, rodeado de ruas largas e luminosas, onde circula o "grande mundo" londrino - muito perto de Oxford street, de Regent Street, de Trafalgar Square e do Strand. É uma massa de três ou quatro andares, construídas sem plano, com ruas tortuosas, estreitas e sujas onde reina uma animação tão intensa como nas principais ruas que atravessam a cidade, com a diferença que, em St. Giles, só se vê pessoas da classe operária. O mercado está instalado nas ruas: cestos de legumes e de frutos, 
todos naturalmente de má qualidade e dificilmente comestíveis, ainda reduzem a passagem, e deles emana, bem como dos açougues, um cheiro repugnante. As casas são habitadas dos porões aos desvãos, são tão sujas no exterior como no interior e têm um tal aspecto que ninguém as desejaria habitar. Mas isto ainda não é nada comparado às habitações nos corredores e vielas transversais onde se chega através de passagens cobertas, e onde a sujeira e a ruína ultrapassam a imaginação; não se vê, por assim dizer, um único vidro inteiro, as paredes estão leprosas, os batentes das portas e os caixilhos das janelas estão quebrados ou descolados, as portas - quando as há - são feitas de pranchas velhas pregadas umas à outras; aqui, mesmo neste bairro de ladrões, as portas são inúteis porque não há nada para roubar. Em toda parte montes de detritos e de cinzas e as águas vertidas em frente às portas acabam por formar charcos nauseabundos. É aí que habitam os mais pobres dos pobres, os trabalhadores mal pagos, com ladrões, os escroques e as vítimas de prostituição, todos misturados. A maior parte são irlandeses ou descendentes de irlandeses, e os que ainda não se submergiram no turbilhão desta degradação moral que os rodeia, mergulham nela cada vez mais, perdem todos os dias um pouco mais da força para resistir aos efeitos desmoralizantes da miséria, da sujeira e do meio ${ }^{16}$.

A partir deste relato, compreende-se o fato de não ter demorado muito a haver reações dos operários, principalmente através de greves e rebeliões, reivindicando direitos que, paulatinamente, foram sendo conquistados através de leis protetoras e que deu embasamento ao surgimento dos ideais socialistas e do sindicalismo.

16 ENGELS, Friedrich. A situação da classe trabalhadora na Inglaterra. 2. ed. Tradução de Rosa Camargo Artigas e Reginaldo Forti. São Paulo: Global. 1988. p. 39. 
Dessa forma, o movimento socialista, mormente o científico de Karl Marx, a doutrina social da Igreja, com a edição da encíclica Rerum Novarum, em 1891, pelo Papa Leão XIII, as greves operárias, a revolução russa de 1917 e a implantação do primeiro Estado Socialista da história, dentre outros, foram fatores importantes que causaram o fim do Estado liberal clássico ${ }^{17}$.

As injustiças sociais levaram o Estado para uma postura mais intervencionista o que se nota, nitidamente, com a leitura da Constituição Mexicana de 1917, que foi a primeira a atribuir aos direitos trabalhistas a qualidade de direitos fundamentais. Em 1919, foi editada a Constituição de Weimar que instituiu novos direitos sociais e econômicos, lançando as bases da democracia social ${ }^{18}$.

A grande depressão e a queda da bolsa de Nova York, em 1929, resultaram em uma intervenção do governo, com profundidade, nas relações econômicas e sociais com objetivo de implantar uma maior igualdade material entre os homens e de assegurar a justiça social, garantindo o direito ao trabalho, à previdência, à educação e à saúde, dentre outros direitos sociais. Tudo isso caracterizou o Welfare State, na tentativa de superar as contradições históricas derivadas do liberalismo clássico, tendo firmado suas bases após a Segunda Guerra Mundial, nos países componentes do bloco ocidental $^{19}$.

O Estado Social priorizou os direitos econômicos, sociais e culturais que são os direitos positivos ou de segunda geração, podendo-se citar a instituição do salário mínimo, a fixação da jornada de trabalho, a proteção em face do desemprego, invalidez ou morte, a aposentadoria e o direito à greve $^{20}$.

Com as atrocidades cometidas durante a Segunda Guerra Mundial e a comoção resultante do holocausto, conduziram à criação da Organização das Nações Unidas, em 1945, com a assinatura da Carta de São Francisco. Em 1948, a ONU editou a Declaração Universal dos Direitos do Homem, considerado um Bill of Rights da humanidade. Este documento, embora não seja um tratado e por isso não vincula os Estados membros da ONU, exerceu forte influência na elaboração dos instrumentos nacionais e internacionais de tutela dos direitos humanos ${ }^{21}$.

17 CARVALHO. Op. cit. p. 43.

18 Ibidem. p. 43.

19 Ibidem. p. 44.

20 GABRIEL. Op. cit., pp. 40-41.

21 GABRIEL. Op. cit., p. 42. 
Não se deve olvidar, todavia, dos antecedentes à Declaração Universal dos Direitos do Homem, que também tiveram sua importância como marcos do processo de internacionalização dos direitos humanos, como foi o caso da Liga das Nações e a Organização Internacional do Trabalho, o Direito Humanitário (conjunto de leis e costumes de guerra) previsto pela Convenção de Genebra de 1864.

A Declaração Universal dos Direitos do Homem, no entanto, é considerada o divisor de águas ao consolidar o movimento de internacionalização dos direitos humanos, buscando a proteção integral do ser humano, multiplicação e universalização desses direitos.

Prevê os direitos de liberdade ${ }^{22}$ - civis e políticos contra o risco de interferência arbitrária do Estado na esfera individual -, igualdade - sociais, econômicos e culturais -, os princípios do Estado liberal e democrático e os princípios do Estado social em seu bojo, lado a lado, por essa razão dizse que ela adotou a concepção de indivisibilidade e interdependência dos direitos humanos, ressaltando a garantia das condições mínimas de vida ${ }^{23}$.

Em conseqüência, o tratamento conferido aos direitos humanos no âmbito interno das constituições dos Estados perdeu força tendo em vista a tendência atual e cada vez maior no sentido de universalização e proteção internacional dos direitos do homem. Isso não significa que os Estados não devem promover a proteção dos direitos humanos no plano interno tendo em vista que a atuação dos órgãos internacionais só iniciam-se quando os Estados falharem ${ }^{24}$.

Esta corresponderia, na visão de Norberto Bobbio, a terceira e última etapa da evolução dos direitos humanos ${ }^{25}$.

22 Liberdades negativas: liberdade de locomoção, de pensamento, de opinião, de religião, de voto, de propriedade, entre outros.

23

24

CARVALHO. Op. cit. p. 45.

GABRIEL. Op. cit. p. 43.

25 Assinala o referido autor a existência de três etapas na evolução dos direitos do homem: a primeira diz respeito à formulação filosófica, da doutrina do jusnaturalismo, que teve em John Locke seu principal e primeiro formulador na era moderna. A segunda é a do acolhimento pelo direito positivo e legislações dessa doutrina desenvolvida, sendo as Declarações de Direitos da revolução americana e francesa as maiores expressões dessa fase, quando, positivados, valem no interior dos Estados que os reconheceram. A terceira, conforme já se verificou, é a que toca a questão da internacionalização dos direitos humanos através de inúmeros tratados internacionais. BOBBIO, Norberto. A Era dos Direitos. 11 ed. Tradução de Carlos 
Tal lógica estrutura-se na consciência de que se os direitos humanos não forem respeitados em todos os lugares, não existirão condições efetivas para o estabelecimento de uma paz reinante na Terra. Inclusive, a própria noção de soberania dos Estados é contestada ante essa tendência de intenacionalização ${ }^{26}$.

Nesta etapa de internacionalização, chama a atenção a capacidade processual adquirida pelos indivíduos para pleitear direitos na esfera internacional. Atribui-se aos órgãos de supervisão, criados pelos tratados, "capacidade para empreender investigações, requisitar informações dos governos e para elaborar relatórios tendentes à correção de violação a direitos humanos, bem como o sistema de petições individuais e interestatais, noticiando fatos relevantes" 27 .

Este movimento identifica que a democracia e a estabilidade internacionais não podem ser alcançadas enquanto existirem diferenças gritantes entre nações ricas e as pobres, povos exploradores e explorados. Urge, portanto, a necessidade de se enfatizar o direito ao desenvolvimento, à paz, ao meio ambiente e qualidade de vida, à conservação e utilização do patrimônio histórico e cultural da humanidade são alçados à condição de novos direitos humanos, consagrando-se, assim, os direitos de solidariedade na consciência internacional ${ }^{28}$.

Hoje, constata-se uma mudança no discurso de atuação do Estado. Após o término da Guerra Fria, realizou-se, em 1993, em Viena, a Conferência Mundial sobre Direitos Humanos que deu origem a uma declaração de cunho mais abrangente mais coerente como o processo contínuo de globalização econômica.

Declarou-se o fim do Estado-providência, a mitificação do estado mínimo, e articulou-se a defesa da necessidade de redução da atuação do Estado. O objetivo é liberar a economia das ingerências normativas do poder público e equilibrar o orçamento do Estado, criando condições mais adequadas ao bom funcionamento do mercado, o que levou a uma flexibilização dos direitos trabalhistas e exacerbada privatização e desmonte da previdência social, aumentando o desemprego e o empobrecimento da classe média. Tudo isso faz aumentar o risco de inviabilizar o exercício da soberania e, em última análise, da própria cidadania e com ela os direitos Nelson Coutinho. Rio de Janeiro: Campus, 1992. p. 30.

26 CARVALHO. Op. cit. p. 46.

27 GABRIEL. Op. cit. p. 43.

28 CARVALHO. Op. cit. p. 47. 
humanos ${ }^{29}$.

É preciso resgatar o debate acerca da importância da afirmação dos direitos humanos e conscientizar a população dos seus direitos para poderem pressionar os governos no sentido de revitalizar as políticas públicas e não se perder todas as conquistas já realizadas.

\subsection{O Fundamento}

Os fundamentos dos direitos humanos e o seu peculiar estatuto na ordem jurídica é uma questão que emerge, sobretudo, na atuação e trabalho do jurista, do juiz e do legislador, neste final de século, em virtude da conscientização crescente da sociedade civil no que se refere aos seus direitos fundamentais ${ }^{30}$.

Os direitos humanos têm seu fundamento antropológico na idéia das necessidades humanas. Com o seu reconhecimento, exercício e proteção, pretende-se satisfazer uma série de exigências que se consideram necessárias para o desenvolvimento de uma vida digna ${ }^{31}$.

Ocorre que um número significativo de autores sempre associou os direitos humanos com sinônimos de direitos naturais, afirmando que os primeiros seriam a versão moderna dos últimos. Dessa forma, constata-se que por detrás do debate sobre os fundamentos dos direitos humanos existe a forte associação feita com os direitos naturais e a crença de serem estes o modelo justificador do direito positivo. Em razão disso, percebe-se que se tornava necessário desenvolver um modelo teórico que pudesse estruturar logicamente os direitos humanos com a ordem jurídica positiva, buscando-se uma solução que prescindisse o modelo do jusnaturalismo, mas que respondesse à questão da fundamentação do direito e, em especial, dos direitos humanos ${ }^{32}$.

Importante, então, resgatar o debate em torno da fundamentação dos direitos humanos já que este esteve, por muito tempo, aniquilado diante do debate político interno e da categorização dos direitos humanos como direitos subjetivos públicos. Ao longo do século XX, com a proliferação de declarações internacionais e de legislações nacionais asseguradoras dos direitos, o conflito existente entre os valores e a prática

29 GABRIEL. Op. cit. p. 48-52.

$30 \quad$ BARRETO. Op. cit. p. 343

31 FERNANDEZ. Op. cit. p. 79.

32 BARRETO. Op. cit. p. 344-345. 
política e jurídica, reflexo do insucesso dos diferentes sistemas jurídicos em estabelecer garantias reais para a observância desses dispositivos legais, levou a uma reflexão sobre os fundamentos dos direitos humanos, que somente tornou-se relevante e inseriu-se no plano de uma reflexão metajurídica, quando "as violações desses direitos na prática quotidiana trouxeram consigo um alto grau de relativismo na sua interpretação e provocaram uma conseqüente insegurança nas relações entre os estados e no seio da própria sociedade civil $^{33}$.

Verifica-se, pois, a necessidade de discutir a fundamentação dos direitos humanos como forma de responder ao argumento autoritário bem como conferir ao direito positivo uma reflexão que vá além da subordinação racional a princípios e valores relacionados com a dignidade humana, estabelecendo-se um patamar metajurídico na análise do direito. Ademais, "a reflexão sobre os fundamentos dos direitos humanos reside, em última análise, na busca da fundamentação racional, portanto universal, dos direitos humanos, que sirva, inclusive, para justificar ou legitimar os próprios princípios gerais de direito" 34 .

Certo é que em relação aos direitos humanos existem também deveres e obrigações fundamentais que devem ser respeitadas. Ademais, o exercício dos direitos humanos já reconhecidos não é ilimitado, podendo ser restringido no que tange à defesa da dignidade, da segurança, da liberdade ou simplesmente da convivência social, ressaltando que essas restrições, porém, devem estar regulamentadas juridicamente para não serem tomadas como arbitrariedade do poder político ${ }^{35}$.

A questão da fundamentação dos direitos humanos está relacionada à questão da justificação racional destes direitos e é importante tanto para a elaboração de uma teoria dos direitos humanos como para a sua prática política, o que acaba por refletir na sua tutela e proteção ${ }^{36}$.

Eusebio Fernandez, com muita propriedade, em sua obra Teoria de la justicia y derechos humanos, discorre sobre as três grandes fundamentações filosóficas que embasaram a teoria dos direitos humanos, quais sejam: a fundamentação jusnaturalista que consiste na consideração dos direitos humanos como direitos naturais; BARRETO. Op. cit. pp. 345-346.

34 Ibidem. p. 348.

35 FERNANDEZ. Op. cit. p. 80.

36 Ibidem. p. 82-83. 
a fundamentação historicista que considera os direitos humanos como direitos históricos e a fundamentação ética que visualiza os direitos humanos como direitos morais ${ }^{37}$.

Passa-se, então, a traçar, em linhas gerais, um pouco do conteúdo de cada uma das mencionadas fundamentações, valendo-me dos ensinamentos do supracitado autor.

\subsubsection{A Fundamentação Jusnaturalista}

A fundamentação jusnaturalista é a mais conhecida e de maior tradição histórica. Ela deriva diretamente da crença e defesa do jusnaturalismo como teoria que fundamenta e explica a existência do direito natural.

Caracteriza-se basicamente pela distinção entre direito natural e direito positivo e pela superioridade do direito natural sobre o direito positivo, já que os direitos naturais seriam inerentes ao ser humano, anteriores e superiores às normas escritas e, portanto, inalienáveis e absolutos.

Atenta para o fato de que a influência do direito natural racionalista, de cunho ontológico, ao longo da história dos direitos humanos aparece em uma série de juristas e filósofos do século XVII e XVIII, como Grocio, Pufendorf, Spinoza, Hobbes, Locke, Rousseau, Wolff e Kant, sendo que, para todos eles, o que chamamos hoje de direitos humanos, era vislumbrado como direitos naturais. Além disso, para todos eles, a idéia dos direitos naturais aparece estreitamente conectada à teoria do contrato social.

A influência jusnaturalista também se faz notar nas declarações de direitos do século XVIII.

Contudo, a fundamentação jusnaturalista dos direitos humanos gera problemas de aceitação por parte da corrente contemporânea da Filosofia e teoria do Direito. As principais críticas levantadas são:

a) que os direitos naturais somente podem ser considerados autênticos direitos no sentido técnico-jurídico do termo quando se encontram reconhecidos pelo direito positivo. Assim, quando os partidários da fundamentação jusnaturalista falam de direitos naturais anteriores e superiores ao direito positivo, deve-se entender que estes representam exigências éticas ou princípios jurídicos suprapositivos, Ibidem. p. 84. 
que são aqueles efetivamente anteriores ao direito positivo e, inclusive, superiores do ponto de vista ético ou moral. Logo, não se pode afirmar tratar-se de uma superioridade jurídica já que seria equivocado pensar o direito natural como direito no mesmo sentido do direito positivo;

b) a idéia de natureza humana não é um conceito claro nem preciso, assim, encontra-se falha a apresentação e defesa dos direitos naturais como sendo aqueles deduzidos da natureza humana. O correto seria dizer que os direitos naturais consistem em deduções que fazemos a partir de juízos de valor que aplicamos à natureza humana;

c) deve-se ter em conta que a invariabilidade, a permanência e a independência das condições históricas dos direitos naturais chocamse com a experiência histórica já que o conteúdo e a importância dada aos direitos humanos varia conforme o momento vivenciado. A lista de direitos humanos modifica-se de acordo com as mudanças ocorridas nos interesses, necessidades, classes no poder, dos meios disponíveis para sua realização, das transformações técnicas, entre outros. Portanto, o que parece fundamental em uma época ou em certa civilização não é fundamental em outras épocas e outras culturas, concluindo-se que não existem direitos fundamentais essencialmente por sua natureza;

d) é ingênua e insuficiente a afirmação de que os direitos humanos existem e são detidos pelos sujeitos independentemente de reconhecimento ou não pelo Direito Positivo. Sem este reconhecimento e amparo pelo ordenamento jurídico, não se vislumbra a sua efetividade e a sua tutela de forma eficaz;

e) por último, a idéia defendida de que a única fundamentação possível dos direitos humanos é a jusnaturalista também é rechaçada já que se deve falar em outras fundamentações, não sendo, portanto, esta a única ${ }^{38}$.

\subsubsection{A Fundamentação Historicista}

Para esta fundamentação, os direitos humanos expressam-se como sendo variáveis e relativos a cada contexto histórico vivenciado pelo homem e de acordo com o desenvolvimento das sociedades.

Com base nela, fala-se em direitos de origem social enquanto resultados da evolução da sociedade. Consequentemente, os direitos humanos não se fundam em sua natureza humana, mas sim nas FERNANDEZ. Op. cit., pp. 85-99. 
necessidades humanas e nas possibilidades de satisfazê-las dentro de uma sociedade, respeitando-se sempre o princípio da dignidade da pessoa humana.

A fundamentação historicista dos direitos humanos, assim considerada, descreve a evolução e o desenvolvimento dos direitos humanos.

Porém, não deixa de estar sujeita também a críticas, como, por exemplo, ao indagar-se se a variabilidade histórica dos direitos humanos é tão ampla como se pretende defender. Constata-se que tal variabilidade é bem aplicada aos direitos econômicos, sociais, culturais e os civis e políticos. No entanto, no tocante aos direitos da personalidade, como o direito à vida e à integridade física e moral, não se deve realizar mesmo raciocínio.

Outro ponto diz respeito à consideração dos direitos humanos como satisfação de necessidades humanas. O que se critica é que seria inconcebível reconhecer e garantir todo o tipo de necessidade, sendo necessário eleger aquelas que sejam mais fundamentais.

E, por fim, sendo os direitos humanos, mas também fundamentais, não seria correto considerá-los relativos face ao contexto histórico vivenciado, pois pereceria o caráter fundamental deles ${ }^{39}$.

Estes são questionamentos e críticas não respondidos pela fundamentação historicista. Por outro lado, não se quer afastar a noção de que os direitos humanos são, sim, fruto da evolução da história da civilização humana e, por isso, sujeitos a evolução e modificação, o que deu base à classificação em gerações de direitos humanos.

Destaca o professor Vicente Barreto que existe uma atenuação nas posições absolutas originais, tanto para os jusnaturalistas, quanto para os historicistas. Os historicistas reconhecem outros direitos mais anteriores aos que surgem no processo de evolução das sociedades, direitos esses que se originaram no próprio processo de formação da sociedade. Os jusnaturalistas, por seu turno, admitem que o progresso da consciência moral é que irá assegurar a explicitação dos direitos naturais, como normas de conduta social, conferindo essa noção temporal de evolução ao seu pensamento. A partir dessas atenuações que foi possível aprovar a Declaração Universal dos Direitos do Homem, pela Assembléia Geral das Nações Unidas, em 1948, com esse denominador comum ${ }^{40}$.

$40 \quad$ BARRETO. Op. cit. p. 350. 


\subsubsection{A Fundamentação Ética}

A fim de responder o questionamento acerca do fundamento dos direitos humanos fundamentais e em nome do quê é feita a sua defesa é que Eusébio Fernandez trabalhou a fundamentação ética ou axiológica.

Ela parte da tese de que a origem e fundamento dos direitos humanos não podem ser jurídicos já que o direito positivo não cria os direitos humanos, mas sim, reconhece-os, convertendo-os em normas jurídicas para a sua salvaguarda.

Dessa maneira, a fundamentação ética perfaz-se na idéia de que a base dos direitos humanos encontra-se em torno de exigências que consideramos imprescindíveis para uma vida digna.

Dessa forma, os direitos humanos aparecem como direitos morais, como exigências éticas e direitos que os seres humanos têm pelo fato de serem indivíduos, independentemente de qualquer contingência histórica ou cultural, característica física ou intelectual, poder político ou classe social. Identifica-se a fundamentação ética dos direitos humanos com valores e exigências éticas que respaldam estes direitos, valores relativos à dignidade humana, valores de segurança, liberdade $\mathrm{e}$ igualdade.

O qualificativo moral aplicado aos direitos representa tanto a idéia de fundamentação ética como uma limitação no número e conteúdo dos direitos que se depreende do conceito de direitos humanos. Observado dessa forma, somente os direitos morais, aqueles que se aproximam mais da idéia de dignidade humana, podem ser considerados como direitos humanos fundamentais e justificados racionalmente.

Com essa fundamentação, escapa-se das contradições sempre suscitadas entre jusnaturalismo e positivismo e da necessidade ou não do reconhecimento pelo ordenamento jurídico, muito embora se admita ser o fundamento dos direitos humanos anterior ao direito positivo, mas sem a noção de ser este fundamento necessariamente e unicamente jusnaturalista ${ }^{41}$.

\section{Os Direitos Humanos de $3^{\mathrm{a}}$ Geração}

No que tange aos direitos fundamentais, eles surgem a cada etapa FERNANDEZ. Op. cit. p. 104-115. 
da história, o que já nos foi apresentado pela fundamentação historicista dos direitos humanos, por essa razão fala-se em gerações de direitos fundamentais.

Ressalva que merece espaço neste estudo diz respeito à crítica que muitos autores fazem a essa classificação, já que os direitos humanos, em sua essência, são universais, indivisíveis, interdependentes e inter-relacionados, o que leva a sua exigibilidade como um todo, complementam-se e acumulam-se. Ademais, a divisão em gerações não é estanque uma vez que as preocupações sociais, por exemplo, já estavam contidas nas reivindicações da Revolução Francesa e não apenas a partir do aparecimento do Estado Social - Welfare State, e não devem sugerir uma hierarquia entre os direitos ${ }^{42}$.

Discordando de tal posicionamento, o professor Vicente Barreto sustenta que existe sim uma hierarquização nos direitos humanos o que se relaciona diretamente com os problemas suscitados quanto às suas garantias efetivas, verificando-se uma escala de valores que comporta graus de proteção e havendo somente pouquíssimos direitos com proteção absoluta, o que vem sendo debatido no que se chamou de aporias relativas à hierarquização desses direitos e aporias relacionadas com a própria natureza desses direitos ${ }^{43}$.

A despeito das ressalvas acima destacadas, o que se pretende com essa classificação em gerações, por outro lado, é, além do caráter didático, tão somente especificar que os direitos do homem são direitos históricos, pois surgem em certas circunstâncias, caracterizados por lutas em defesa de novas liberdades, de modo gradual, acompanhando o progresso técnico, ou seja, o progresso da capacidade do homem de dominar a natureza e os outros homens.

Logo, os direitos de terceira geração não poderiam ter sido sequer imaginados quando foram propostos os de segunda da mesma forma que estes não seriam concebíveis quando do surgimento dos direitos de primeira geração ${ }^{44}$.

Sucintamente, segue-se uma exposição do conteúdo das $1^{\mathrm{a}}$ e $2^{\mathrm{a}}$ gerações, uma vez que as mesmas já foram tratadas no tópico referente à trajetória histórica dos direitos humanos.

Compreendem os direitos da $1^{\text {a }}$ geração aqueles que dizem 42 PAIM. Op. cit. p. 62.

43 BARRETO. Op. cit. p. 357.

44 BOBBIO. Op. cit. p. 5-7. 
respeito às liberdades dos indivíduos, sendo os direitos civis e políticos nela incluídos (liberdades individuais oponíveis ao Estado, como limitadores de sua atuação, sendo direitos negativos na medida em que o Estado deve abster-se de perturbar o seu exercício, tais como o direito à vida, à liberdade, à propriedade e à resistência que foram as bases de reivindicações das revoluções liberais).

Os direitos da $2^{\mathrm{a}}$ geração são considerados os direitos de igualdade, em decorrência do surgimento do Estado do Bem-Estar Social e salvaguarda dos direitos trabalhistas e sociais reivindicados.

São os direitos sociais, econômicos e culturais, como o direito à saúde, à educação, ao trabalho e ao lazer. A finalidade é concretizar uma liberdade material entre os homens e, para tanto, o Estado passa a interferir nas relações econômicas privadas. Pode-se chamá-los de direitos prestacionais ou de natureza positiva eis que são realizados através de uma atuação positiva do $E \operatorname{stado}^{45}$, isto porque exigem para a sua efetividade uma atuação provedora do Poder Executivo, sua concretização depende da realização de políticas públicas o que, obviamente, diretamente vinculado à previsão orçamentária destinada para tal finalidade.

Enquanto os direitos civis e políticos encontram-se protegidos por remédios processuais já consagrados, podendo-se recorrer ao Judiciário em casos de violação pelo Estado de suas liberdades, os direitos sociais, culturais e econômicos, por seu turno, dependem muito mais de uma ação política do que jurídica ${ }^{46}$.

Analisando os direitos de $3^{\mathrm{a}}$ geração, destaca-se a sua importância para o presente estudo em razão da valoração dada ao meio ambiente e ao seu equilíbrio, visando à proteção do patrimônio natural às futuras gerações para que possam satisfazer as suas necessidades.

No século XX, a experiência das duas Guerras Mundiais, os danos causados ao meio ambiente, a acirrada competição econômica travada entre as nações, a explosão demográfica, tudo isso foi matriz propulsora para o surgimento dos chamados direitos de $3^{\mathrm{a}}$ geração.

A complexidade das relações sociais trouxe a consciência de que uma vida digna requer um cuidado com sua qualidade, exaltando-se os aspectos coletivos ${ }^{47}$.

45 CARVALHO. Op. cit. p. 49.

46 GABRIEL. Op. cit. p. 44-45.

$47 \quad$ PAIM. Op. cit. p. 61. 
Direito à paz, à preservação do meio ambiente, à autodeterminação dos povos, entre outros, foram direitos que se desenvolveram principalmente em sede de Tratados Internacionais, propulsores da universalização dos direitos humanos ${ }^{48}$.

Portanto, os direitos de $3^{\mathrm{a}}$ geração foram firmados recentemente na história e estão assentados nos valores de solidariedade ou fraternidade. Têm como titulares não as pessoas individualmente consideradas, mas sim o gênero humano diante da sua tamanha importância para a manutenção da harmonia no planeta, tendo emergido o conceito de interesse comum da humanidade (Resolução $n^{\circ} 34-53$ da Assembléia Geral das Nações Unidas, dezembro de 1988).

Norberto Bobbio definiu a titularidade desses direitos, em particular, observando que ocorreu uma passagem da consideração do indivíduo humano no seu singular, que foi o primeiro sujeito ao qual se atribuíram direitos, para uma consideração de toda a humanidade em conjunto e até mesmo para sujeitos diferentes do homem, como os animais. "Nos movimentos ecológicos, está emergindo quase que um direito da natureza a ser respeitada ou não explorada, onde as palavras "respeito" e "exploração" são exatamente as mesmas usadas tradicionalmente na definição e justificação dos direitos do homem"

Não obstante encontrarem-se ainda em elaboração, já foram identificados, ao menos, cinco direitos: o direito ao desenvolvimento, o direito à paz, ao meio ambiente, ao patrimônio comum da humanidade e à comunicação ${ }^{50}$.

Infelizmente, ainda não é satisfatória a proteção desses direitos por se tratarem de direitos difusos ou de titularidade coletiva, esperandose por uma maior eficácia neste campo neste novo século que se inaugura, principalmente no sentido de se estabelecer metas passíveis de serem atingidas com o intuito de erradicar a pobreza, promover a justa distribuição de riqueza e viabilizar a satisfação das necessidades básicas de todos em termos de moradia, educação, saúde, emprego, lazer etc, elaborar leis favoráveis ao gozo dos direitos; engendrar remédios constitucionais que viabilizem ao cidadão comum exigir perante o Poder Judiciário a observância e o atendimento de seus direitos pelo Estado; democratizar a gestão pública para maior participação no $48 \quad$ GABRIEL. Op. cit. p. 41.

$49 \quad$ BOBBIO. Op. cit. p. 69.

$50 \quad$ CARVALHO. Op. cit. p. 50. 
acompanhamento das políticas públicas sociais traçadas. ${ }^{51}$

Em decorrência da massificação social que ocorre atualmente, os direitos humanos vêm se ampliando como resposta da sociedade às dificuldades crescentes, já se falando até em uma $4^{\text {a }}$ geração de direitos humanos, referentes aos efeitos mais traumáticos da pesquisa biológica e conseqüente manipulação do patrimônio genético.

Além disso, há que se considerarem também os efeitos trazidos pela globalização no sentido de seus benefícios serem revertidos em favor de toda a humanidade e buscar mecanismos de efetivação dos direitos fundamentais com a idéia de universalização dos mercados ${ }^{52}$.

Até agora, o processo de globalização, infelizmente, produziu muito mais excluídos do que globalizados, aumentando o desemprego, a violência e a fome em diversos países, notadamente os inseridos no rol dos subdesenvolvidos. Logo, ao invés de viabilizar o exercício da soberania dos Estados, ela tem aumentado o risco de anular a cidadania e os direitos humanos.

4. O meio ambiente ecologicamente equilibrado como direito fundamental

Primeiramente, antes de adentrar no estudo do meio ambiente como direito fundamental e direito humano, interessante faz-se esclarecer o seu conceito.

Sabendo-se que o meio ambiente possuiu um aspecto artificial, constituído pelo espaço urbano construído; um aspecto cultural, representado pelo patrimônio histórico, artístico, arqueológico, paisagístico e turístico; e um aspecto natural ou físico, formado pelo solo, água, ar, flora, enfim, pela interação dos seres vivos e seus meios, passa-se, então, a conceituar o que seria propriamente o meio ambiente, valendo-se, para tanto, dos ensinamentos de José Afonso da Silva:

O meio ambiente é, assim, a interação do conjunto de elementos naturais, artificiais e culturais que propiciem o desenvolvimento equilibrado da vida em todas as suas formas. A integração busca assumir uma concepção unitária do ambiente, 
compreensiva dos recursos naturais e culturais. ${ }^{53}$

O direito ao meio ambiente saudável e equilibrado possui expressa previsão na Constituição Federal, que o elevou ao status de direito fundamental imanente à vida das presentes e futuras gerações (caput do art. $225)^{54}$ e o determinou como princípio geral da ordem econômica brasileira (art. 170, inc. VI, da CF) ${ }^{55}$.

A proteção do meio ambiente, como já foi previamente analisado, vem inserida no rol de direitos fundamentais de $3^{\mathrm{a}}$ geração, direitos de solidariedade e fraternidade que têm como titular não um indivíduo nem determinado grupo, mas sim o gênero humano ${ }^{56}$, por isso também poder-se atribuir a ele a classificação de direito humano.

Traçando-se um paralelo com os direitos humanos, pode-se afirmar que o direito ambiental possui todas as principais características dos direitos humanos, quais sejam: é um direito geral por se aplicar a todos os seres humanos sem distinção; é mais importante do que os direitos não fundamentais por representar, juntamente com os demais direitos humanos, a base para aqueles e por ser condição para sobrevivência humana; é essencial independentemente do tempo ou lugar e, assim, é imutável em seu valor e importância.

Com efeito, verifica-se que o ponto tangencial entre o direito ao meio ambiente ecologicamente equilibrado e os direitos humanos está na fundamentação de ambos que é o direito à vida e à saúde, com vistas a garantir uma vida saudável. Logo, só é possível viver com qualidade e saúde

53 SILVA, José Afonso da. Direito Ambiental Constitucional. 4. ed. São Paulo: Malheiros Editores. 2005. p. 20.

54 "Todos têm direito ao meio ambiente ecologicamente equilibrado, bem de uso comum do povo e essencial à sadia qualidade de vida, impondo-se ao Poder Público e à coletividade o dever de defendê-lo e preservá-lo para as presentes e futuras gerações."

55 BAZAN, Luís Henrique Ayala. Direito ao desenvolvimento sustentável homogêneo e heterogêneo. Breve análise no federalismo brasileiro. Jus Navigandi, Teresina, a. 9, n. 633, 2 abr. 2005. Disponível em: <http://jus2.uol.com.br/doutrina/ texto.asp?id=6558>. Acesso em: 23 set. 2005.

56 SILVA, José Afonso da. Fundamentos Constitucionais da Proteção do Meio Ambiente. Revista de Direito Ambiental, São Paulo: Ed. Revista dos Tribunais, ano 7, jul./set. 2002. p. 51-52. 
se o meio ambiente estiver equilibrado ${ }^{57}$.

Dessa forma, o meio ambiente ecologicamente equilibrado, indubitavelmente, passa a integrar o rol dos direitos humanos. Tal conclusão parte da premissa de que a tutela do meio ambiente é um meio instrumental através do qual se visa a proteger um valor maior que é a qualidade de vida. Está-se, pois, diante de uma nova projeção do direito à vida, já que nele há de ser incluída a manutenção das condições ambientais que são suportes da própria vida ${ }^{58}$.

Ressalte-se que o direito à qualidade de vida como direito fundamental é reconhecido desde a Declaração Universal dos Direitos do Homem em 1948, em seu artigo XXV ${ }^{59}$, bem como pela Declaração do Meio Ambiente adotada pela Conferência das Nações Unidas, em Estocolmo, em junho de 1972.

Ao se tratar do direito a meio ambiente como direito humano, estáse estabelecendo um vínculo do desenvolvimento com os direitos humanos, direito a condições dignas de vida e ao meio ambiente sadio e ecologicamente equilibrado como meio de atender as necessidades das presentes e futuras gerações, o que se perfaz como pressuposto para o respeito e concretização do desenvolvimento sustentável e para a formação de cidades sustentáveis. ${ }^{60}$

O meio ambiente ecologicamente equilibrado correlaciona-se, como já se destacou acima, diretamente com a noção de qualidade de vida que, por seu turno, depende de condições objetivas e subjetivas para ser definida, o que dificulta sobremaneira sua conceituação.

É certo que vai além dos conceitos de salubridade, saúde, segurança, infra-estrutura e desenho urbano. Importante notar que a qualidade de vida vai incorporar, principalmente, as possibilidades de atendimento dos anseios dos indivíduos que a procuram e isso traz ínsita a imagem que cada indivíduo dela constrói, de acordo com seus interesses, objetivos e expectativas de vida.

Na lição de Carla Capena, para conceituar a qualidade de vida, devem ser levados em consideração quatro aspectos: aspectos espaciais, biológicos, sociais e econômicos que irão variar e alterar-se à medida que os atores, com seus interesses, objetivos e expectativas modificam-se. Assim, melhor 57

58 SILVA, José Afonso da. Direito Ambiental Constitucional. 4. ed. São Paulo: Malheiros Editores. 2005. p. 58.

59 CAPENA, Carla. Cidades Sustentáveis. In: GARCIA, Maria (coord.) A Cidade e seu Estatuto. São Paulo: Juarez de Oliveira, 2005. p. 140.

$60 \quad$ CAPENA. Op. cit. p. 150. 
definição será aquela que se pautar na sensação de bem estar do indivíduo. Entretanto, esta sensação está sujeita a fatores objetivos e externos e subjetivos e internos, dos quais o indivíduo dificilmente conseguirá escapar, tais como prazer, conforto, privacidade, segurança, o papel social ou status, a liberdade ${ }^{61}$, acesso à tecnologia, serviço de saúde eficaz, moradia, só para citar alguns.

Dessa forma, conceituar qualidade de vida torna-se tarefa muito difícil diante da dificuldade em se estabelecer quais critérios mínimos que mereceriam ser atendidos de modo geral, já que essa sensação de bem estar do indivíduo varia de pessoa para pessoa, de classe social para classe social, de localidade para localidade.

O importante é ter sempre a consciência de que o direito à vida, como matriz de todos os demais direitos fundamentais do Homem, deve ser o vetor para a proteção do meio ambiente, devendo estar acima de quaisquer outras considerações.

Vale registrar alguns dos principais documentos internacionais que previram o meio ambiente como direito humano e direito fundamental, resultado da conscientização que levou à necessidade de se conferir base legal ao meio ambiente no âmbito internacional.

A Declaração de Estocolmo, 1972, organizada pela ONU, resultado da Conferência de Estocolmo, além de reconhecer expressamente o direito ambiental como direito fundamental ${ }^{62}$, instituiu o Programa das Nações Unidas sobre Meio Ambiente.

A Carta Africana dos Direitos Humanos e dos Direitos dos Povos de 1981 teve sua importância por ser a primeira convenção a afirmar o direito dos povos à preservação do equilíbrio ecológico ${ }^{63}$.

A Carta Mundial da Natureza de 1982 que estabeleceu uma série de princípios dirigidos à humanidade por ser esta parte da natureza e a vida depende do funcionamento ininterrupto dos sistemas naturais.

CAPENA. Op. cit. p. 139.

62 "Princípio I. O homem tem direito fundamental à liberdade, à igualdade e ao desfrute de condições de vida adequada em um meio ambiente de qualidade tal que lhe permita levar uma vida digna e gozar de bem-estar, e é portador solene de obrigação de melhorar esse meio ambiente, para as gerações presentes e futuras. A esse respeito as políticas que promovam ou perpetuem o apartheid, a segregação racial, a discriminação, a opressão e dominação estrangeira continuam condenadas e devem ser eliminadas." 
A Comissão Mundial sobre o Meio Ambiente ou Comissão Brundtland, de 1987 que também em seu princípio I definiu o direito a um meio ambiente adequado à saúde e bem-estar como direito fundamental todos os seres humanos, além de definir o conceito de desenvolvimento sustentável, como sendo aquele atende as necessidades do presente sem comprometer as gerações futuras em relação à satisfação das suas próprias necessidades.

O Protocolo Adicional à Convenção Americana sobre Direitos Humanos em matéria de Direitos Econômicos, Sociais e Culturais de 1988, ou Protocolo de São Salvador que inovou ao incluir em seu texto que os Estados signatários devem promover a proteção, preservação e melhoramento do meio ambiente.

A Declaração do Rio de Janeiro e a Agenda 21 provêm da Conferência das Nações Unidas sobre Meio Ambiente e Desenvolvimento ou ECO-92.

A primeira trouxe a correlação que faltava entre desenvolvimento sustentável e meio ambiente ecologicamente equilibrado, e a segunda consiste em um plano global para o século XXI, com ênfase na gestão ambiental descentralizada e participativa, focalizando o plano regional e priorizando uma mudança comportamental do ser humano perante a natureza, que não pode mais ser vista como uma mercadoria inesgotável.

A Convenção sobre a Diversidade Biológica, de 5 de junho de 1992, analisa a questão da conservação da diversidade biológica como sendo um interesse comum da humanidade e a utilização sustentada de seus componentes além da repartição justa e eqüitativa dos benefícios derivados das utilização e exploração dos recursos genéticos, com a adequada transferência de tecnologias, visando, em especial, à preservação de animais e espécies vegetais em seu habitat natural.

Por fim, a Convenção sobre Mudança do Clima, firmada pela ECO92, que estabeleceu normas para redução na emissão de gases poluentes que aceleram o efeito estufa e a destruição da camada de ozônio e o Protocolo de Kyoto que veio, em 1997, para ratificar os ditames da Convenção do Clima. Inovou o Protocolo ao lançar a idéia de banco para emissão de carbono, que poderá ser quantificado monetariamente e negociado entre as nações signatárias.

Com essa explanação, mencionando-se todos os principais documentos pertinente à temática ambiental, conclui-se pela hodierna vital importância que lhe conferida no âmbito internacional, o que precisa ser concretizado na esfera regional, de acordo com as especificidades de cada 
localidade.

Por outro lado, ainda faz-se necessária buscar uma verdadeira conscientização da sociedade e dos governos para efetivar esse direito ambiental, o que demanda a participação de todos os atores sociais e exige uma mudança comportamental do ser humano, o que será debatido logo a seguir, ao se cuidar da questão da ética ambiental.

\section{A Ética Ambiental}

É mister, neste momento, analisar a questão da ética nas relações ecológicas, a qual, obviamente, não se limita apenas a discutir quem deve suportar o ônus da preservação, o que será visto neste tópico.

A questão principal a ser desenvolvida transcende a titularidade da preservação e prescinde de uma mudança comportamental do ser humano em relação à natureza.

Mais abrangente que a dimensão normativa, a angulação moral, sem dúvida alguma, impõe uma nova ética que objetiva afastar a visão de ser a sociedade um mercado consumidor e o meio ambiente como uma mercadoria a ser comercializada sem critérios ou freios, de maneira predatória e irresponsável ${ }^{64}$.

Segue-se, adiante, uma breve análise da ética ambiental, apresentando alguns dos seus aspectos, tendo sido adotado em grande parte, como base do presente estudo, a abordagem elaborada por José Roque Junges em sua obra "Ética Ambiental".

Percebe-se, portanto, que, atualmente, diante da crise ecológica que se apresenta mundialmente, as questões ambientais não dependem simplesmente de soluções técnicas como solução, mas pedem uma resposta ética, o que se verifica pelo crescente debate em torno da consciência e sensibilidade ecológicas que surgiram como reação a uma mentalidade predatória da natureza, mormente por se saber que os recursos naturais não são uma fonte infinita e ilimitada, à disposição para livre exploração.

Com base nesse raciocínio que surge o dever moral de utilizar os bens naturais de forma equilibrada, solidária e harmônica, afastando-se de vez a idéia que permeou o processo socioeconômico da origem do capitalismo, onde a ideologia predominante era utilizar os recursos naturais disponíveis e tirar o máximo de proveito imediato e o mais rapidamente possível.

64 SÉGUIN, Elida. Direito Ambiental: nossa casa planetária. 2. ed. Rio de Janeiro: Forense, 2002. p. 125. 
Em conseqüência, foram surgindo enfoques antropocêntricos ou biocêntricos na discussão ética da ecologia, afirmando os primeiros que o ser humano é uma figura protagonista no mundo e os problemas ambientais seriam resolvidos sob a perspectiva do papel central do homem em relação à natureza e tem como ponto de partida o ser humano em sua moralidade.

Já os biocêntricos defendem que o ser humano é apenas um elemento a mais no ecossistema da natureza, um elo entre muitos na cadeia de reprodução da vida, entendendo a ecologia como conhecimento e prática de preservação do meio ambiente. Apresenta-se como a única postura coerente de defesa da natureza e preservação do meio ambiente.

Essas são as duas grandes tendências de ética ecológica. Note-se que elas excluem-se entre si. Importante ressaltar, outrossim, que as dificuldades ecológicas só serão equacionadas com a construção de uma sociedade justa e igualitária, priorizando e valorizando a vida em sentido amplo ${ }^{65}$.

$\mathrm{O}$ antropocentrismo admite a existência de deveres humanos em relação à natureza, mesmo que de forma indireta, ou de uma responsabilidade dos homens pelos recursos naturais em prol das gerações futuras. Defende o estabelecimento de limites e regras para a intervenção na natureza e o uso dos recursos naturais para o bem dos próprios seres humanos. Todavia, as restrições pautam-se nos interesses, necessidades ou preferências humanas e não na natureza, seu equilíbrio ou harmonia ${ }^{66}$.

Fala-se em éticas conservacionistas ou preservacionistas conforme o tipo de interesse humano em destaque.

As éticas de conservação baseiam-se em medidas coercitivas drásticas que limitam as nações ricas em seu consumo e as nações pobres em sua população, pensando a humanidade como um todo sem levar em consideração a preservação do ecossistema. Busca a sobrevivência da civilização e não da biosfera natural ${ }^{67}$.

As éticas de preservação apontam para valores não-materiais da natureza, sendo esta detentora de valor científico por ser fornecedora de conhecimentos inestimáveis para a pesquisa, para encontrar a excelência moral do ser humano e para fornecer normas de comportamento. O estudo da natureza, sob esta perspectiva, possibilita a formulação de uma ética natural. As éticas de preservação podem ser divididas em modelos. O 65 JUNGES, José Roque. Ética Ambiental. São Leopoldo: Editora Usininos, 2004. p. 7-10.

66 Ibidem. p. 13-14.

$67 \quad$ Ibidem. p. 15. 
primeiro focaliza a importância da proteção da natureza para a formação e a consolidação da identificação civil e cultural de um grupo nacional, já que são necessários símbolos que se associam a essa identidade, como o são os elementos da natureza. O segundo acredita estar no conhecimento da natureza a base para a formação do caráter moral dos seres humanos, visualizando a ecologia como ciência que ensina a conhecer os níveis de interdependência dos diferentes elementos de um ecossistema, preservando o equilíbrio e prevendo conseqüências de uma intervenção humana. O terceiro, por seu turno, privilegia a fruição das belezas naturais porque, dessa forma, a contemplação do belo levaria o ser humano a melhorar o seu caráter. $\mathrm{O}$ último modelo preza por uma ecologia profunda que afirma não se poder reduzir a crise ambiental exclusivamente a um conflito ético porque demanda uma mudança de paradigmas conceituais e de percepção do mundo ${ }^{68}$.

A conclusão a que se chega é que o modelo do homem egoico, compreendido como indivíduo isolado e separado do mundo, encarando a natureza como um objeto que se encontra a seu dispor, cria patologias ambientais. A partir da superação da concepção do ser humano como espécie dominante é que surge o ser humano ecóico em vez do egoico.

Percebe-se, com esta breve explanação, que a ecologia profunda ainda se encontra entre as éticas ecológicas que têm o ser humano como ponto de partida já que se fundamenta na mutação do paradigma de percepção da natureza por parte do ser humano. Apesar disso, ela é significativa por privilegiar a vida como enfoque para a construção do discurso ético ${ }^{69}$.

O biocentrismo, por sua vez, defende a existência de deveres diretos e indiretos do ser humano para com o meio ambiente que passa a ser titular de direitos.

Existem dois tipos de tendências éticas antiantropocêntricas: biocentrismo mitigado e o biocentrismo global ou ecocentrismo.

$\mathrm{O}$ biocentrismo mitigado defende que entidades individuais, detentoras de vida e de sensações, merecem a tutela moral porque são titulares de direitos. Assim, há quem defenda que os animais são sujeitos de vida e, portanto, detentores de autonomia e identidade; há quem afirme que os animais são receptáculos de dor e prazer e há aqueles que estendem a consideração moral aos seres biologicamente organizados e não apenas aos que têm sensações, dando igual consideração a todos os viventes. Porém, essa posição individualizada dos seres vivos é totalmente inviável e 68 JUNGES. Op. cit.p. 17-21.

$69 \quad$ Ibidem. p. 22. 
problemáticas para uma visão ecológica ${ }^{70}$.

O biocentrismo global ou ecocentrismo é fortemente antiantropocêntrico e holístico, não fazendo analogias entre humanos e nãohumanos para defender suas posições, como acontece com o biocentrismo mitigado quando fala de sujeito moral ou de direitos de seres individuais. Parte dos conhecimentos científicos da ecologia, do reconhecimento da natureza como um conjunto interdependente para chegar a normas em relação ao meio ambiente. Assim, passa a merecer consideração moral não apenas entidades individuais, como também conjuntos sistêmicos: ecossistemas, biosfera, cadeias alimentares, fluxos energéticos.

Ele valoriza a vida enquanto tal, como um processo global e que depende de inter-relações para sua reprodução, o que se explica pelo equilíbrio existente nos ecossistemas em decorrência das cadeias alimentares. Inspira-se, portanto, na ética do respeito à vida, defendendo uma moral de solidariedade e de simpatia a toda a forma de vida.

Também pode ser vislumbrada a ética biocêntrica global no modelo chamado Ética da Terra, proposto por Aldo Leopold em 1949. Para ele, uma atitude é moralmente justa quando pretende preservar a integridade, a estabilidade e a beleza da comunidade biótica. Sua ética está fundada no fato de pertencer a comunidades bióticas, às quais estão todos os seres ligados como membros. Sendo a Terra uma comunidade biótica, deve-se respeito e empenho à sua preservação e manutenção do equilíbrio ${ }^{71}$.

$\mathrm{O}$ ecocentrismo assume uma posição antiantropocêntrica porque se contrapõe à idéia do homem auto-suficiente e onipotente, produzido pela modernidade, descontextualizado de iter-relações com seu entorno humano e das interdependências do seu ambiente natural. Considera este homem o responsável pelo desastre ecológico que vivenciamos.

É claro que o homem, por ter consciência e intenção ética, possui um papel fundamental no contexto da biosfera e isso não se pretende negar aqui. Por isso que a ética ecológica centra-se naquilo que o homem pode e deve fazer para preservar o meio ambiente natural. Em razão disso que se configura equivocado afastar totalmente da questão ecológica eis que o desafio ambiental consiste exatamente na mudança de atitude do ser humano perante a natureza, que não pode ser reduzida a atender apenas aos interesses humanos, não deve ser vista como um objeto por ser ela a matriz da vida ${ }^{72}$. $70 \quad$ Ibidem. p. 24-27.

71 JUNGES. Op. cit. p. 27-33

72 Ibidem. p. 64-66. 


\section{Conclusões}

A partir de tudo o que foi exposto neste trabalho, pode-se chegar a algumas conclusões acerca da temática envolvida.

Primeiramente, verificou-se que o longo caminho traçado pelo reconhecimento e tutela dos direitos humanos culminou em inúmeros direitos positivados pelo ordenamento jurídico interno dos Estados, mediante Declarações e Constituições, e por tratados internacionais, decorrentes do recente processo de internacionalização e universalização dos direitos humanos.

Esses direitos ganharam força e notoriedade o que foi conquistado por meio de muitas lutas, revoluções e esforço para sua salvaguarda.

Foram classificados em gerações, o que não significa que eles sejam estanques ou valorizados somente naquele momento histórico. Pelo contrário, estão em constante evolução e surgimento e complementam-se, o que só faz aumentar o rol de direitos consagrados e resguardar a dignidade do homem, a sua qualidade de vida, sendo estas as suas bases.

Contudo, toda a ideologia promovida e divulgada pelo discurso de garantia e implementação dos direitos humanos está se esvaziando em decorrência do veloz processo de globalização que, se por um lado traz muitos benefícios como uma maior conexão entre as nações o que pode levar a uma interferência de um Estado em outro para fins de fazer prevalecer a proteção dos direitos humanos, por outro lado deixa claro que o interesse maior sempre em jogo é o econômico.

Portanto, não se pode permitir que séculos de conquistas em termos de reconhecimento e tutela dos direitos humanos percam-se frente à ganância de muitas nações movidas por um sistema capitalista quase que irracional, que visa apenas ao lucro e à acumulação de riquezas.

Dessa forma, busca-se um despertar de consciência dos atores sociais, envolvendo os governos, as comunidades, os ativistas, as organizações não governamentais, entre outros, para que comecem a agir em conjunto em prol dessa mudança de paradigma, da mudança de comportamento e atitude.

Sabe-se que a erradicação total da pobreza, o fim da segregação espacial e racial ainda estão longe de se efetivarem. Nem por isso os indivíduos devem acometer-se da desesperança, do desânimo ou do conformismo. Basta olhar para trás e observar que grandes transformações e mudanças requerem persistência e observância dos ideais. 
Não se pretende, contudo, negar a existência de atuação de diversos grupos e governos neste sentido. É certo que eles ganham espaço a cada dia e suas conquistas já começam a ter caráter multisetorial e atingem mais de um lugar ao mesmo tempo.

$\mathrm{O}$ que se quer é lançar o desafio de uma verdadeira atuação em conjunto com vistas a compreender diversas localidades do planeta, atingir povos que têm seus direitos humanos diariamente violados, implantar uma ação global e perseguir a paz mundial a todo custo.

Em relação ao direito ambiental, constata-se, outrossim, a urgente atuação do homem no que tange a evitar maiores danos à natureza. É mister um controle maior pelos Estados da exploração dos recursos naturais, notadamente os recursos não renováveis. Necessário também se faz a elaboração de instrumentos mais eficazes para essa fiscalização e, acima de tudo, é importante haver uma conscientização do homem para que vislumbre na natureza o devido valor que a ela deve ser conferido.

Sem essa mudança, não adianta querer falar em desenvolvimento sustentável, em meio ambiente ecologicamente equilibrado ou na herança do patrimônio natural deixada para as futuras gerações.

\section{Referências Bibliográficas}

BARRETO, Vicente. Os Fundamentos Éticos dos Direitos Humanos. Revista de Direito Comparado, Belo Horizonte, v. 2, n. 2, pp. 343-359, março, 1998.

BAZAN, Luís Henrique Ayala. Direito ao desenvolvimento sustentável homogêneo e heterogêneo. Breve análise no federalismo brasileiro. Jus Navigandi, Teresina, a. 9, n. 633, 2 abr. 2005. Disponível em: <http://jus2. uol.com.br/doutrina/texto.asp?id=6558>. Acesso em: 23 set. 2005.

BOBBIO, Norberto. A Era dos Direitos. 11 ed. Tradução de Carlos Nelson Coutinho. Rio de Janeiro: Campus, 1992.

CAPENA, Carla. Cidades Sustentáveis. In: GARCIA, Maria (coord.) A Cidade e seu Estatuto. São Paulo: Juarez de Oliveira, 2005.

CARVALHO, Oscar de. Gênese e Evolução dos Direitos Humanos Fundamentais. Revista do Instituto de Pesquisas e Estudos - Divisão Jurídica, 
Bauru, n. 34, pp. 31-52, abril/julho, 2002.

ENGELS, Friedrich. A situação da classe trabalhadora $n$ Inglaterra. 2. ed. Tradução de Rosa Camargo Artigas e Reginaldo Forti. São Paulo: Global. 1988.

FERNANDEZ, Eusébio. Teoria de la justicia y derechos humanos. Madrid: Editorial Debate, 1991.

GABRIEL, Antônio José Martins. Direitos humanos e globalização: conquistas e desafios. Revista do Ministério Público, Rio de Janeiro, n. 19, pp. 37-63, jan. Jun., 2004.

JUNGES, José Roque. Ética Ambiental. São Leopoldo: Editora Usininos, 2004.

OLIVEIRA, Glauberson Aquino. A perspectiva ambiental diante do desenvolvimento econômico. Disponível em: http://www.ambito-juridico. com.br/aj/damb0002.htm. Acesso em: 06/09/2005.

PAIM, Maria Augusta Fonseca. Direitos Humanos e Meio Ambiente. Revista Jurídica. Campinas: Faculdade de Direito da PUC de Campinas, v. 19, n. 1, 2003.

SÉGUIN, Elida. Direito Ambiental: nossa casa planetária. 2. ed. Rio de Janeiro: Forense, 2002.

SILVA, José Afonso da. Direito Ambiental Constitucional. 4. ed. São Paulo: Malheiros Editores. 2005.

- Fundamentos Constitucionais da Proteção do Meio Ambiente. Revista de Direito Ambiental, São Paulo, a. 7, n. 27, pp. 51-58, jul./set. 2002. 